\title{
A sociologia urbana, os modelos de análise da metrópole e a saúde coletiva: uma contribuição para o caso brasileiro
}

\author{
Urban sociology, analytical models \\ for metropolisses, and collective health: \\ a contribution to the Brazilian case
}

Alberto Lopes Najar 1

Eduardo César Marques ${ }^{2}$

1 Departamento

de Ciências Sociais, ENSP/

Fiocruz. Rua Leopoldo

Bulhões, 1480/917,

Manguinhos, 21041-210,

Rio de Janeiro RJ.

najar@ensp.fiocruz.br

2 Departamento de Ciência

Política, Universidade

de São Paulo e Centro

Brasileiro de Pesquisa.
Abstract In light of the historical relationship between epidemiology and geographic space and the relevance of a detailed examination of models for the production of cities, this article systematizes the notions of space/territory that have influenced urban sociology since the 1970s in Brazil. The principal analytical models for large Brazilian cities are discussed in such disciplines as urban sociology, human geography, regional economics, and urban planning. The article suggests that the distribution of public investments bears a close relationship to the social structure crystallized in space. The text attempts to expand the basis for a dialogue between the literature underlying the analyses of so-called socio-spatial inequalities and collective health. Two key points are raised in the article: there are increasingly available computational techniques leading to more widespread use of variables that are amenable to spatial expression; but, these facilities lack a more sociological or humanistic approach for both the methodological design and the results of such analyses.

Key words Socio-spatial inequalities, Collective health, Geographic space, Social sciences and health.
Resumo À luz da antiga relação entre a epidemiologia e o espaço geográfico e dos diversos modelos de produção das cidades, apresenta-se uma sistematização das noções de espaço/território, a partir da década de 1970 no Brasil. Discutem-se os principais modelos analiticos das grandes cidades brasileiras, cujas raízes conceituais encontram-se em disciplinas como a sociologia urbana, a geografia humana, a economia regional e o planejamento urbano. Sugere-se que a distribuição de investimentos públicos guarda relação com a estrutura social cristalizada no espaço. Procura-se ampliar as bases de um diálogo entre a literatura que apóia as análises das chamadas desigualdades socioespaciais e a saúde coletiva. Apresenta-se sugestão de arcabouço para o desenvolvimento de tipologias de análise socioespacial. Considera-se que se encontram disponiveis diversas técnicas computacionais que popularizam o emprego de variáveis passíveis de expressão espacial. No entanto, essas facilidades ressentem a falta de um aporte mais sociológico, ou humanistico.

Palavras-chave Desigualdades socioespaciais, Saúde coletiva, Espaço geográfico, Ciências sociais e saúde 


\section{Introdução}

Desde a origem da epidemiologia, admite-se que o espaço geográfico mantém com os fatos da saúde relações determinantes. Podem-se citar alguns escritos hipocráticos, especialmente o magnífico "Aires, águas e lugares" (Hippocrates, 1998), assim como os elucidativos mapas de John Snow, que permitiram demonstrar a ligação inequívoca entre a epidemia de cólera e a distribuição de água (Snow, 1990). Mais recentemente, a distribuição espacial de determinadas neoplasias coloca em evidência aglomerados (clusters) de ocorrência, trazendo para debate a ação patógena de centrais de incineração, usinas nucleares, linhas de transmissão, pontos de difusão de campos eletromagnéticos etc. (Wynder, 1988; Mattos, 2002; Koifman, 1998). Seria pleonástico enumerar exemplos de como a epidemiologia vem utilizando a dimensão espacial como fator explicativo ou distintivo para ponderar os pesos de fatos genéticos e ambientais.

Existem numerosas definições de espaço e território, algumas opostas, outras complementares. Não se fará neste artigo uma revisão ou mesmo uma taxonomia de definições e usos dessas palavras no âmbito das ciências sociais, especialmente pelo fato de que são conceituações ainda suficientemente distantes de um consenso; o leitor interessado poderá consultar particularmente Santos (1988) e Verdier (2002). O motivo recorrente do presente artigo é o de apresentar uma sistematização da noção do que chamar-se-á aqui de espaço/território, tomada de empréstimo pela saúde pública, e em particular pela epidemiologia, de outras disciplinas, em especial da sociologia urbana, da geografia humana, da economia regional e do planejamento urbano, certamente por motivos de ordem histórico-política, e que, por sua importância instrumental, pode ajudar em uma contextualização do tripé tempo, lugar e pessoa. O objetivo precípuo será, então, apresentar as principais formulações a respeito do espaço urbano que, no Brasil, formam verdadeiros paradigmas analíticos, exatamente pela sua capacidade explicativa.

A noção de espaço/território permite considerar uma dimensão complementar que não é apenas articulada em torno dos conceitos de tempo, distância e acessibilidade. Administrar, governar, dirigir são atividades que demandam freqüentemente, no que se refere a territórios no interior de uma metrópole, um recorte territorial, uma re-definição de espaços em rela- ção aos quais se constroem identidades. A reflexão sobre os limites territoriais, as implicações dos recortes, que atores/sujeitos sociais estariam envolvidos, são questões em relação às quais as ciências humanas em geral, as ciências sociais aplicadas e, em particular, a sociologia urbana têm muito a contribuir.

Que os problemas de saúde pública e das dimensões territoriais da saúde podem transformar-se em questões geopolíticas diversos trabalhos já o demonstraram cabalmente (Monmonier, 1993; Hérodote, 1999). No caso brasileiro, embora se tenham feito grandes avanços de investigação no campo das técnicas e no campo metodológico (Najar \& Marques, 1998 e Carvalho, 2001), muitas relações ainda restam a ser exploradas, especialmente no que se refere às questões de análise empírica, de forma que possam efetivamente resultar em informações que se consolidem em competência coletiva do setor saúde pública no sentido de apoiar a tomada de decisões.

Em outras palavras, mais do que qualquer outra atividade do setor terciário, a localização criteriosa dos serviços de saúde é essencial como aspecto operacional do conceito de equidade, e isso fica mais evidente quando se passa a considerar, por exemplo, os serviços de urgências médicas. Os modelos clássicos de análise espacial construídos a partir do conceito de distância/tempo podem ajudar a otimizar a distribuição dos serviços no espaço, mas estão longe de permitir uma abordagem mais complexa da situação (Vaguet, 2001).

Esses modelos foram utilizados em estudos espaciais da assistência médica que trabalham a partir de considerações normativas, particularmente aqueles procedimentos com aspectos de localização, distribuição das atividades dos serviços de saúde e de fornecimento de serviços de saúde. A maior parte dos estudos parte da Teoria de Localização Central ou do Lugar Central, estando implícito o entendimento de que, para se alcançar o serviço necessário, um paciente tem de se deslocar até uma instalação de saúde apropriada. Assim, o sistema de serviços de saúde pode ser visto como uma hierarquia teórica de localizações, com graus equivalentes de atuação. A distância percorrida variará de maneira regular, dependendo tanto da abrangência do serviço, quanto das especialidades oferecidas. Essas questões têm levado ao desenvolvimento de modelos de alocação espacial em estudos de geografia da assistência à saúde (Vasconcellos, 1997). 
As escolhas políticas em termos de atendimento à população, independente do setor considerado da infra-estrutura urbana-metropolitana e da distribuição de quaisquer serviços, estão indelevelmente impressas no espaço/território, que nesse sentido pode ser considerado corpo do tempo. O estudo dos modelos espaciais pode revelar dimensões bastante interessantes, especialmente quando a investigação se pauta pela interseção com a epidemiologia.

\section{Uma perspectiva histórica}

A saúde pública brasileira é profundamente marcada por preocupações espaciais desde seus primórdios. A origem das intervenções urbanas no Brasil esteve relacionada de forma direta a intervenções sanitárias. Durante e em conseqüência das epidemias de cólera e febre amarela de 1849-1853, as primeiras intervenções normatizadoras sobre o urbano foram adotadas, conforme pode ser observado em Andrade (1986) e Machado et al. (1978). Naquele momento, os campos disciplinares e profissionais estavam pouco definidos, e o espaço urbano e a saúde pública eram objeto integrado de intervenção para os profissionais do higienismo. $\mathrm{Na}$ virada do século, cerca de 50 anos depois, as ações sobre o urbano mesclavam discursos embelezadores com outros de cunho sanitário, e as estratégias de intervenção misturavam obras viárias e de transportes com ações de polícia médica e de imunização.

Segundo alguns estudos de história do urbanismo, como Andrade (1992 e 1993), o urbanismo moderno no Brasil teria tido início justamente com os trabalhos de engenheiros sanitaristas como Saturnino de Brito e Aarão Reis nos anos de 1890 e 1900, e não com arquitetos brasileiros influenciados por Corbusier na década de 1930, como sustentavam autores como Cardoso (1988). Em relação ao campo próprio da saúde, ao contrário, a hegemonia já estava claramente definida pela corporação médica, em parte como resultado de um longo processo iniciado em meados do século 19.

Nas décadas seguintes, o processo de delimitação dos campos de ação se intensificou, afastando os engenheiros do desenho, planejamento e gestão urbana, localizando-os, então, nas infra-estruturas e na funcionalidade da cidade. A hegemonia sobre a cidade como um todo coube aos arquitetos, dedicando-se os geógrafos, mais tarde, aos estudos espaciais. As corporações da saúde pública se concentraram cada vez mais nos aspectos nosológicos e de administração e planejamento dos serviços de saúde. Todos esses processos foram cercados de fortes lutas pela hegemonia de cada saber e técnica de intervenção, conforme podemos observar em Ribeiro (1993), Dias (1994) e Silva (1994).

Conseqüência desse processo, a temática espacial ficou de fora das preocupações centrais da saúde pública, sendo tratada como elemento de contextualização. A percepção do espaço parece ter passado a ser a de um papel em branco sobre o qual se desenvolveriam fenômenos e processos. Essa visão não é exclusiva da saúde, mas é partilhada por outras áreas de conhecimento nas quais o binômio espaço/território cumpre papel muito mais central, como a economia urbana e regional, por exemplo.

A partir da década de 1980, a saúde pública brasileira parece ter retomado seu interesse direto pelo espaço e pela cidade, trazendo o urbano mais para o centro das análises. Esse movimento aconteceu com a descoberta de relações estreitas entre o nosso padrão de produção dos espaços urbanos, as condições de vida dele advindas e o quadro de morbi-mortalidade vigente nas metrópoles brasileiras. Durante o período, parece ter ocorrido uma convergência nas literaturas críticas de origem marxista sobre a saúde e o urbano, com forte ênfase nos processos de expropriação e de funcionalidade, tanto da saúde como do urbano, dos processos de acumulação na sociedade capitalista. Sob essa classificação muito generalizante, podemos incluir estudos tão diferenciados, mas ao mesmo tempo tão parecidos, como Castells (1981), Lojkine (1981), Jaramillo (1986), Illich (1975) e Breilh e Granda (1983).

\section{A moda metropolitana carioca: do Rio para o Brasil}

Na década de 1970, foram produzidos no Rio de Janeiro diversos trabalhos sobre estruturação intra-urbana, consolidando um modo de entender as metrópoles brasileiras que exerceria forte influência sobre os estudos e pesquisas posteriores em todo o Brasil. Merece destaque, nesse sentido, o trabalho Ipea/Ibam (1976), que consolida extensa pesquisa realizada no Instituto Brasileiro de Administração Municipal. Esse estudo tinha caráter eminentemente operacional, associando-se aos esforços para a pro- 
dução de mecanismos técnicos de gestão dos aglomerados metropolitanos em todo o Brasil, criados pela lei complementar 14/1974; e, mais especificamente, para as áreas da região metropolitana do Rio de Janeiro, incorporadas a um único poder estadual com a fusão dos estados do Rio de Janeiro e da Guanabara em julho de 1974 (lei complementar 20/1974). O trabalho representou um marco por inovar as análises sobre aglomerados metropolitanos: a estruturação do aglomerado metropolitano do Rio de Janeiro e de seu entorno foi descrita e analisada como um núcleo metropolitano forte e hipertrofiado, no qual se concentravam serviços e recursos econômicos, e uma vasta periferia, que se organizava de forma concêntrica em um gradiente decrescente de recursos e integração com o núcleo. A região metropolitana do Rio de Janeiro seria, então, composta de quatro anéis: o núcleo, as periferias imediata, intermediária e distante.

$\mathrm{O}$ trabalho que divulgou esse modelo de forma ampla foi publicado dois anos mais tarde por Santos e Bronstein (1978), depois da realização de um seminário organizado pelo Banco Nacional de Habitação (BNH) e pelo Instituto Brasileiro de Administração Municipal (Ibam). Esses autores estavam interessados no estudo da relação entre o modelo de desenvolvimento adotado pós-1964 e a organização dos espaços metropolitanos: o Rio de Janeiro está servindo e servirá cada vez mais de modelo de metropolização para as cidades brasileiras. Em outros termos, o Rio tende a ditar a moda metropolitana (Op. cit.), que seria - ou é? uma tendência a desenvolver núcleos hipertrofiados cercados de periferias crescentemente carentes de serviços e de infra-estrutura, habitados por população de baixa renda. Segundo essa formulação, o Rio de Janeiro e outras cidades brasileiras se estruturariam de forma oposta às cidades americanas. Os ricos, aqui, amontoam-se próximos da infra-estrutura existente no centro da metrópole, e os pobres habitam cidades-dormitório distantes e carentes. Esse modelo, talvez por sua simplicidade e capacidade operacional, exerceu, e continua exercendo, influência sobre estudos dos mais variados matizes, desde o excelente trabalho de Abreu (1987) sobre a construção histórica do espaço carioca, até trabalhos na área da epidemiologia como Duchiade (1991) e Leal (1995), e planejamento em saúde (Galvão et al., 1999).

O modelo núcleo-periferias concêntricas para o Rio de Janeiro tinha inicialmente objeti- vos meramente instrumentais e de descrição geral e, nesse contexto, poderia ser considerado apropriado. A sua utilização posterior, no entanto, ultrapassou em muito aqueles objetivos, tornando-o problemático. Primeiramente porque a aplicação do modelo levou a certo determinismo das estruturas sobre o espaço. Isso fica claro, por exemplo, quando Santos (1980) afirma que podem ser verificadas, nas grandes cidades brasileiras, as formas de estruturação espacial correspondentes à implantação e ao desenvolvimento do capitalismo no país. Excessivamente genérica, a afirmação, ao mesmo tempo em que diz tudo, não diz nada, pois, sem dúvi$\mathrm{da}$, as relações sociais se inscrevem concretamente nos espaços. Se assim não fosse, todos os países do Terceiro Mundo teriam seus espaços construídos de forma semelhante, e isso não ocorre porque o espaço herdado constrange os atores sociais em suas práticas e relações. O espaço, assim como acontece com as instituições, produz ao mesmo tempo em que é produzido pela sociedade. Essa dialética é intrínseca, visto que o espaço é uma das dimensões da vida (e, portanto, da sociedade), o que torna impossível descobrir quem produz ou reproduz quem.

O segundo problema de utilização do modelo é de natureza metodológica: excessivamente simplificador da complexidade metropolitana, levou boa parte das análises a tratar como similares espaços dessemelhantes sob o ponto de vista de sua composição e constituição social. Já no início da década, Vetter (1981) advertia que talvez seja interessante passar a pensar em termos de um sistema de núcleos e periferias, uma vez que a estrutura interna da cidade parece muito mais variada do que poderia ser explicada por uma simples estrutura núcleoperiferia. Marques (1993) pôde comprovar a existência, já em 1980, de conteúdos sociais diversos em espaços considerados homogêneos pela literatura. A estruturação interna da região metropolitana do Rio de Janeiro era aparentemente não-concêntrica e não-contígua entre espaços com conteúdos sociais similares, assemelhando-se muito mais a um mosaico complexo do que a um gradiente decrescente de círculos concêntricos. Esse aspecto também se revelou em outras análises, particularmente em Najar (1997 e 2000): o aglomerado metropolitano comandado pela cidade do Rio de Janeiro se apresentou, não como uma cidade segregada, partida, mas como uma heterópolis, no sentido de Jencks (1993), um verdadeiro e sofisticado mosaico urbano (Timms, 1971), marcado 
tanto por dégradés quanto por dicotomias, desautorizando-nos a pensar o espaço urbano carioca como uma cidade dual, visto que ele se nos apresentava como uma cerzidura, um mosaico complexo, bem mais próximo ao que parece ter-se transformado a própria sociedade brasileira nas últimas décadas. Resultados também confirmados por outros trabalhos indicam, por exemplo, que há bairros e favelas dentro de uma mesma favela (Preteceille e Valladares, 2000; Vetter, 1981 e o clássico Machado da Silva, 1967). Especialmente com relação às favelas cariocas, os resultados recomendam que se deve ter cuidado ao se discutir a periferização das favelas em relação à metrópole. Como seria possível, então, incorporar em um modelo a enorme complexidade dessa realidade?

\section{Modelos analíticos socioespaciais}

Pode-se dividir a literatura relevante sobre a estruturação intra-urbana em grandes cidades em três grandes grupos. O primeiro deles se compõe da extensa bibliografia que se dedica a estudar o crescimento histórico das cidades, tentando descrever as diversas dinâmicas encontradas. Esses estudos são patrimônio da tradição arquitetônica/urbanística e recebem normalmente a designação de estudos sobre forma urbana. Essa produção não será discutida aqui e será referida e utilizada à medida que ajudar a esclarecer questões relativas à história e à geometria dos aglomerados urbanos (Morris, 1984; Linch, 1974).

Um segundo grupo aborda a estruturação interna das cidades com caráter propositivo e normativo. Trata-se de análises que, mesmo quando voltadas para o passado, pretendem projetar ou planejar o futuro das cidades. Nessa linha, podemos incluir toda a tradição urbanística e do planejamento urbano stricto sensu, ou seja, a produção de modelos, análises e instrumentos que possibilitam, uma vez implementados, alterar a estruturação urbana em um certo sentido predeterminado (Choay, 1979; Hall, 1990).

O terceiro grupo se refere a tentativas de reprodução, em modelos, do padrão de estruturação urbana percebido e mediado pelos sentidos e pelo pensamento. Esses modelos se apóiam na observação e no estudo de grande número de análises do primeiro grupo (históricos e de forma urbana) e se relacionam com os do segundo tipo (normativos e propositivos), mas consti- tuem um campo próprio com interesses específicos, tanto analíticos quanto explicativos. Abordagens desse tipo são eminentemente teóricas e compostas por dois momentos. Em uma primeira fase, orientadas por hipóteses, produzem um modelo, e, em um segundo momento, orientadas pelos dados, comparam o modelo às situações empíricas. É com esta produção que dialogamos.

O conjunto dos saberes produzidos sobre o urbano assim como sobre a saúde pública não constitui uma matriz disciplinar, como sugere Oliveira (1988), mas uma matriz multidisciplinar, sempre com pretensões transdisciplinares. São campos do conhecimento - emprega-se a expressão entendendo que tais campos são, ou podem ser, constituídos por parcelas menores, a saber, áreas do conhecimento formadas por axiomas, conceitos, categorias, paradigmas e enfoques oriundos de diversas áreas do saber, com perspectivas disciplinares diferenciadas e geralmente com premência de definir e/ou adotar técnicas de intervenção. Esses procedimentos convergem para uma tríade - tempo, lugar e pessoa -, que constitui seu próprio objeto. Essa tríade, por sua vez, desdobra-se, do ponto de vista operacional, em cinco dimensões: uma dimensão temporal, três dimensões espaciais $\mathrm{x}, \mathrm{y}, \mathrm{z}$; e uma dimensão para o indivíduo/populações. Tudo isso inter-relacionado pelo diálogo e coexistência no interior de uma mesma comunidade.

No conjunto de saberes dos estudos urbanos, nem todos produziram modelos de estruturação. Isso se deve às diferentes preocupações presentes, assim como a diferentes posturas com relação à atividade de pesquisa. Tradições de caráter cientificista, por exemplo, tendem a procurar padrões e leis gerais, ao contrário de tradições empiristas. Tradições que não privilegiam a natureza autônoma do espaço urbano, por outro lado, tendem a rejeitar a construção de modelos. A combinação dessas duas características tem definido a existência de diversos modelos. A tradição da sociologia urbana de cepa marxista, por exemplo, apesar de cientificista, nega a autonomia do espaço e, portanto, não produziu modelos (Castells, 1981). O enfoque da geografia brasileira, por outro lado, defendendo a autonomia do espaço, mas adotando postura empirista, também não produziu modelos.

Em função do que foi anteriormente ponderado, não se considerará no presente artigo, três importantes tradições de estudos urba- 
nos: (1) a antropologia urbana de Velho (1975) e Durham (1988), entre outros; (2) as abordagens de talho marxista, quer sociológicas (Lefebvre, 1969; Castells, 1981; Lojkine, 1981), quer dos estudos espaciais (Leborgne e Lipietz, 1990); (3) a geografia brasileira de origem francesa (Monbeig, 1941). Interessam-nos especificamente outras duas tradições: a ecologia urbana e a geografia e economia urbanas. Dada à sua importância para esse ensaio, resume-se a seguir, em largos traços, cada uma das duas.

A chamada ecologia urbana é aplicação ao meio urbano do ferramental analítico da ecologia humana. Sua versão original foi desenvolvida pela Escola de Chicago nas décadas de 1920 e 1930. Essa perspectiva estudou a cidade sob aspectos culturais, comportamentais e espaciais tendo como objetivo último analisar a vida do homem moderno. Segundo Park (1925), um de seus fundadores, a cidade é um estado de espírito, ... é um produto da natureza, $e$ particularmente da natureza humana. Esta natureza seria composta de características biológicas e culturais. Às primeiras estaria associada uma volição à competição, que alocaria os indivíduos no espaço segundo suas aptidões. À segunda estaria relacionada a necessidade de comunicação, a de interação social e da construção de uma ordem moral.

A contribuição dos autores da Escola de Chicago ocorreu em duas direções principais. Em uma primeira linha, os autores da Escola realizaram um extenso trabalho empírico sobre cultura urbana, tentando determinar a especificidade do "urbanismo como modo de vida". Esses estudos enfocaram os diversos comportamentos na comunidade urbana, a vizinhança, a delinqüência, a mobilidade intra-urbana, a vida nos bairros fortemente segregados etnicamente etc. Para Velho (1973), os estudos realizados pelos principais autores do movimento - Robert Park, Ernest Burguess, Rodrick McKenzie e principalmente Louis Wirth - representaram as primeiras análises de sociologia urbana.

Em uma segunda linha de análise, desenvolvida principalmente por McKenzie e Burguess, foi realizado um esforço de generalização, tentando construir uma teoria científica do crescimento urbano e da estruturação espacial baseada nas cidades norte-americanas. Para McKenzie, a localização no espaço não só era produto dos recursos e funções de cada grupo e atividade na competição, como também estava associada a um ciclo ecológico de invasão- competição-sucessão-acomodação, válido não apenas para atividades e residências, mas também para grupos étnicos (ethnic succession e residential invasion). A diferença entre esses processos e as formas naturais de competição (válidas para plantas e animais) estaria na capacidade humana de transformar as condições ambientais.

Ao longo das décadas de 1940 e 1950, Amos Hawley ao fazer nova análise da ecologia urbana reduziu a ênfase na competição e aumentou a importância da cooperação. Para a primeira Escola de Chicago, a estruturação do espaço era um produto da luta dos indivíduos e grupos por recursos escassos; para a segunda versão da tradição ecológica, a distribuição socioespacial seria uma adaptação funcional de cada espaço particular a transformações provocadas na sociedade urbana como um todo. A sociedade seria um sistema que, buscando equilíbrio, imprimiria funções diversas a cada uma de suas partes. Uma transformação em determinada configuração espacial representaria uma mudança homeostática das partes daquele sistema.

De forma aproximadamente concomitante à abordagem ecológica, ganhou expressão, tanto na geografia quanto na economia, outra linha de estudos sobre o espaço urbano com pretensões de constituir uma teoria do urbano, a qual se designa aqui geografia e economia urbanas.

Em 1926, Robert Haig lançou a idéia de uma complementaridade entre renda da terra e custos de transporte. Enfocando os custos de transporte, e não as distâncias, o autor abriu um vasto campo para as análises a partir da idéia de custos de fricção. Estes seriam representados pela soma da renda e do custo de transporte relacionados a cada localização em um dado tempo. Os custos de fricção variariam em função de transformações urbanas e das tecnologias de transporte, mas sua minimização para dado grau de acessibilidade expressaria a localização perfeita para certo uso. O modelo de Haig permitia a explicação de localizações agrícolas e de indústrias, mas não lhe permitia afirmar nada sobre atividades comerciais, indivíduos e famílias. Como afirmou Alonso (1964), O volume de vendas de um comércio varejista varia com a sua localização, e a firma tem que pesar os custos de fricção contra este fator. Os custos de fricção não são por eles próprios suficientes para determinar a localização, a não ser que variações no volume de vendas também sejam considerados de alguma forma custos de fricção. 
De forma paralela e independente, em 1933, Christaller publicou sua Teoria do lugar central, que exerceu forte influência entre economistas e geógrafos. Segundo ela, a função das cidades seria a de fornecer bens e serviços ao seu entorno, denominado região complementar. O motor do processo de crescimento urbano seria o desenvolvimento econômico, que elevaria mais do que proporcionalmente a demanda por seus serviços. A partir das diversas atratividades seria possível construir uma hierarquia de lugares centrais, e a sobreposição das regiões complementares resultaria em um mosaico de hexágonos contíguos cobrindo toda a região. A teoria do lugar central pode ser utilizada também para o contexto intra-urbano e, em especial, intra-metropolitano. O resultado da aplicação desse modelo é um sistema multicentrado de núcleos e periferias em inter-relação e hierarquia. Esse modelo é mais interessante para descrição da estruturação metropolitana moderna do que um modelo concêntrico de inspiração ecológica, apesar de se adequar melhor a atividades econômicas do que a grupos sociais.

No que diz respeito à modelagem da estruturação e dinâmica intra-urbana, a contribuição mais importante da escola neoclássica espacial está nos trabalhos de William Alonso (especialmente Alonso, 1964). Esse autor construiu uma teoria da renda da terra urbana a partir das simplificações características das análises da economia espacial - a redução de todas as escolhas e estratégias individuais ao cálculo econômico racional, a consideração de todas as empresas como firmas indiferenciadas, a inexistência de regulamentações estatais e a desconsideração de quaisquer características topográficas, considerando o território como uma planície isotrópica. Os preços da terra urbana seriam o resultado de um leilão entre os diversos usos (e grupos diferentes de usuários no interior de cada uso). Os diagramas dos preços da terra expressariam as variações dos lances ofertáveis por cada consumidor de localização para cada lugar na cidade. $\mathrm{O}$ orçamento e a estrutura de preferências de cada consumidor (exógena ao modelo como para todo neoclássico), por outro lado, definiriam uma curva de demanda por localização. O encontro das duas curvas - a de lances ofertáveis e a de demanda - definiria a localização ótima para cada consumidor. A renda seria um alocador ótimo de usos, e qualquer regulação e interferência nesse mecanismo de mercado para melhorar a situação de alguém pioraria a de outro, razão pela qual o Estado não deveria interferir regulando os usos do solo.

O modelo espacial resultante é dinâmico e versátil, incorporando diversos fenômenos associados às diferentes curvas de preferências dos agentes econômicos e dos grupos sociais. Não há nenhuma forma urbana específica definida a priori, ao contrário dos modelos ecológicos, mas um resultado contingente da definição das preferências. Com este modelo, tornou-se possível explicar a até então aparentemente contraditória localização de pobres e ricos nas cidades americanas. Pobres se localizariam nas regiões mais centrais e de maior renda da terra por priorizarem a acessibilidade, mesmo que para isso tivessem de consumir pouca terra (áreas de alta densidade), considerando suas limitações orçamentárias. Camadas ricas da população, ao contrário, não se incomodariam com localizações mais distantes (por utilizarem transporte individual) para poderem consumir maiores quantidades de terra. A chave para o entendimento da distribuição dos suburbs estaria no fato de que a acessibilidade é um bem inferior, enquanto a baixa densidade é um bem superior - suas demandas são relativamente inversa e diretamente proporcionais à renda.

Através de sua teoria, Alonso polemizou com os reformadores urbanos da década de 1960 acerca dos planos de reestruturação e revitalização dos centros então em execução. Para Alonso (1974), mesmo depois de revitalizados, os centros não conseguiriam atrair grupos de renda mais alta, visto que seu padrão de vida seria incompatível com as regiões centrais. Essa polêmica é interessante, pois, ao mesmo tempo que demonstra a aplicabilidade do modelo, indica que, aparentemente, Alonso não levou sua capacidade explicativa até às últimas conseqüências, modelando preferências diferenciadas para diversos subgrupos no interior de grupos de renda. Como sugerido em Castells (1994) e Sassen (1991 e 1998), existem grupos sociais específicos de alta renda para quem a localização central está associada a um padrão de vida específico altamente valorado, o que tem levado os centros das chamadas "cidades globais" a um intenso processo de elitização. $\mathrm{O}$ acesso a determinados bens e serviços também pode ser um bem superior. 


\section{Concluindo sem fechar}

Para finalizar, deve-se ter presente que a utilização de modelos espaciais para a descrição do urbano no Brasil se iniciou através dos estudos da geografia. Foi através dessa disciplina que as duas grandes linhas disciplinares descritas anteriormente entraram na literatura brasileira sobre o espaço e o urbano. A tradição geográfica brasileira, no entanto, não guarda nenhuma relação com a produção de modelos abstratos e só recentemente os incorporou. Através da produção geográfica ocorreram a introdução da preocupação com modelos e a convergência em torno da descrição e explicação da estruturação interna das metrópoles brasileiras. Quando esse modelo se constituiu para o caso da região metropolitana do Rio de Janeiro não representava mais um patrimônio da produção geográfica, mas reunia geógrafos, arquitetos, administradores, etc. A sua ancestralidade, no entanto, está ligada diretamente à produção geográfica, mais especificamente a trabalhos como Geiger (1960) e Santos (2001) durante o primeiro momento de transformação da geografia tradicional, e Bernardes e Duarte (1974).

A desigualdade espacial, sendo um aspecto da desigualdade em geral, tem sua importância reforçada quando segregações espaciais e regionais alinham-se com tensões políticas e étnicas. O crescimento da desigualdade espacial está relacionado também a uma maior abertu- ra das economias e a adaptação ao processo de globalização. A sua conseqüência é não só uma submissão à dinâmica global mas também uma imensa diferenciação no interior das grandes metrópoles, o que sugere um modelo analítico que parta da premissa de que a distribuição dos investimentos públicos guarda relação estreita com a estrutura social corporificada no espaço, ou, segundo Vetter (1982), há uma "causação circular" provocada por uma superposição entre renda real e renda monetária. Acrescentamos que essa renda real, no caso das políticas públicas de saúde, são benefícios líquidos que se traduzem em mudanças dos perfis epidemiológicos da população. Dada à melhoria generalizada das condições de vida da população nas grandes cidades brasileiras, tais mudanças só podem ser detectadas, num sentido operacional que interessa grandemente à saúde pública, e especialmente à epidemiologia, caso se trabalhe com níveis de agregação convenientes, por exemplo, setores censitários ou domicílios, que serão posteriormente reagrupados através de técnicas especiais - análise de clusters, por exemplo -, oferecendo assim novas "visões" sobre os aglomerados urbanos, no nosso caso, regiões metropolitanas.

Espera-se ter apresentado o que se acredita ser o arcabouço básico de uma sugestão para o desenvolvimento de tipologias de análise socioespacial no âmbito daquilo que ousamos chamar o lugar do espaço na saúde coletiva.

\section{Referências bibliográficas}

Abreu M 1987. A evolução urbana do Rio de Janeiro. Jorge Zahar Editor. Rio de Janeiro.

Alonso W 1964. Location and land use. Harvard University Press.

Alonso W 1974. The historic and the structural theories of urban: their implications for urban renewal. In C Tilly (org.). An urban world. Little, Brown and Company, Boston.

Andrade C 1986. A cólera-morbo: momento crítico da história da medicina em Pernambuco. Fundação José Bonifácio, Recife.

Andrade C 1992. A peste e o plano: o urbanismo sanitarista do engenheiro Saturnino de Britto. Dissertação de mestrado. Faculdade de Arquitetura e Urbanismo/ USP, São Paulo. 
Andrade C 1993. De Viena a Santos: Camillo Sitte e Saturnino de Britto. In S Camillo. A construção da cidade segundo seus princípios artísticos. Editora Ática, São Paulo.

Bernardes L \& Duarte H 1974. Estrutura espacial e dinâmica interna da área metropolitana do Rio de Janeiro. Cadernos PUC/RJ, 21 (Série História e Geografia).

Breilh J \& Granda E 1983. Ciudad y muerte infantil. Ediciones C.E.A.S., Quito.

Cardoso A 1988. Construindo a utopia: urbanismo e modernidade no Brasil. Dissertação de mestrado. Instituto de Pesquisas e Planejamento Urbano e Regional/UFRJ, Rio de Janeiro.

Carvalho MS \& Nobre FF 2001. Análise de dados espaciais em saúde. Cadernos de Saúde Pública 17(5).

Castells M 1981. A questão urbana. Editora Paz e Terra, Rio de Janeiro.

Castells M 1994. European cities, the informational society and the global economy. New Left Review 204.

Choay F 1979. Urbanismo. Editora Perspectiva, São Paulo.

Dias J 1994. Os engenheiros do Brasil. In J Dias. Engenheiros e economistas: novas elites burocráticas. Editora Fundação Getúlio Vargas, Rio de Janeiro.

Duchiade M 1991. Mortalidade infantil por pneumonia na região metropolitana do Rio de Janeiro 1976-86. Dissertação de mestrado. Escola Nacional de Saúde Pública/Fiocruz, Rio de Janeiro.

Durham E 1988. A sociedade vista da periferia. In L Kowarick (org.). As lutas sociais e a cidade. São Paulo: passado e presente. Editora Paz e Terra, São Paulo.

Galvão RD, Nobre FF \& Vasconcellos MM 1999. Modelos matemáticos de localização aplicados à organização espacial de unidades de saúde. Revista de Saúde Pública 33(4): 422-434.

Geiger P 1960. Ensaio para a estrutura urbana do Rio de Janeiro. Revista Brasileira de Geografia 22(1).

Hall P 1990. Cities of tomorrow. Basil Blackwell, Oxford.

Hérodote 1999. Santé publique et géopolitique. Hérodote 92. La Découverte, Paris.

Hipócrates 1998. Aires, águas y lugares, pp. 18-19. In C Buck, A Llopis, E Nájera \& M Terris (orgs.). El desafio de la epidemiologia: problemas y lecturas seleccionadas. OPAS, Washington, D.C.

Illich I 1975. A expropriação da saúde: Nêmesis da medicina. Nova Fronteira Editora, Rio de Janeiro.

Ipea/Ibam 1976. Região metropolitana do Rio de Janeiro: serviços de interesse comum. Comissão Nacional de Regiões Metropolitanas e Política Urbana, Brasília.

Jaramillo S 1986. Crise dos meios de consumo coletivo urbano e capitalismo periférico. Revista Espaço e Debates 18.

Jencks C 1993. Heteropolis: Los Angeles - the riots and the strange beauty of hetero-architecture. Academy Editions, Londres.

Koifman S, Koifman, RJ \& Meyer, A 2002. Human reproductive system disturbances and pesticide exposure in Brazil. Cadernos de Saúde Pública 18(2):435-445.

Leal MC 1995. Evolução da mortalidade infantil no Estado do Rio de Janeiro na década de 80: o componente neonatal. Tese de doutoramento. Escola Nacional de Saúde Pública/Fiocruz, Rio de Janeiro.

Leborgne D \& Lipietz A 1990. Flexibilidade defensiva ou flexibilidade ofensiva: o desafio das novas tecnologias e da competição mundial. In E Preteceille \& L
Valladares (orgs.). Reestruturação urbana: tendências e desafios. Nobel/Iuperj, São Paulo.

Lefebvre H 1969. O direito à cidade. Editora Documentos, São Paulo.

Linch K 1974. The pattern of the metropolis. In C Tilly (org.). An urban world. Little, Brown and Company, Boston.

Lojkine J 1981. O Estado capitalista e a questão urbana. Martins Fontes, São Paulo.

Machado da Silva LA 1967. A política na favela. Cadernos Brasileiros 9(3):35-47, maio/junho.

Machado R, Loureiro A, Luz R \& Muricy K 1978. A danação da norma: a medicina social e a constituição da psiquiatria no Brasil. Editora Graal, Rio de Janeiro.

Marques E 1993. Desigualdades sociais e infra-estrutura urbana: a produção do saneamento no Rio de Janeiro. Dissertação de mestrado. Instituto de Pesquisas e Planejamento Urbano e Regional/UFRJ, Rio de Janeiro.

Mattos IE, Sauaia N \& Menezes PR 2002. Padrão de mortalidade por câncer em trabalhadores eletricitários. Cadernos de Saúde Pública 18(1):221-233.

Monbeig P 1941. O estudo geográfico das cidades. Revista do Arquivo Municipal de São Paulo 7(73).

Monmonier M 1993. Mapping it out: expository cartography for the humanities and social sciences. The University of Chicago Press, Chicago.

Morris A 1984. Historia de la forma urbana: desde sus orígines hasta la Revolución Industrial. Gustavo Gilli, Barcelona.

Najar AL \& Marques EC 1998. Saúde e espaço: estudos metodológicos e técnicas de análise. Fiocruz, Rio de Janeiro.

Najar AL 1997. Desigualdades sociais e análise espacial: uma aplicação para o município do Rio de Janeiro utilizando sistemas de informações geográficas. Tese de doutorado. Iuperj, Rio de Janeiro.

Najar AL 2000. Rio 40 graus: metodologia de seleção de áreas para minoração de desigualdades de bem-estar e promoção da saúde na região metropolitana do Rio de Janeiro (3 vol.). Fiocruz, Rio de Janeiro.

Oliveira R 1988. Sobre o pensamento antropológico. Tempo Brasileiro, Rio de Janeiro.

Park R 1925. The city: suggestions for the investigation of human behavior in the urban environment. In $\mathrm{R}$ Park, E Burguess \& R McKenzie. The city. The University of Chicago Press, Chicago.

Preteceille E \& Valladares L 2000. A desigualdade entre os pobres - favela, favelas, pp. 459-485. In R Henriques (org.). Desigualdade e pobreza no Brasil. Ipea, Rio de Janeiro.

Ribeiro M 1993. História sem fim... Inventário da saúde pública. Editora UNESP. São Paulo.

Santos C 1980. Velhas novidades nos modos de urbanização brasileiros. In L Valladares (org.). Habitação em questão. Zahar Editor, Rio de Janeiro.

Santos C \& Bronstein O 1978. Metaurbanização: o caso do Rio de Janeiro. Revista de Administração Municipal 25:6-34.

Santos M 1988. Metamorfoses do espaço habitado: fundamentos teóricos e metodológicos da geografia. Hucitec, São Paulo.

Santos P 2001. Formação de cidades na Brasil colonial. Editora UFRJ, Rio de Janeiro. 
Sassen S 1991. The global city: New York, London, Tokyo. Princeton University Press. Nova Jersey.

Sassen S 1998. Globalization and its discontents: essays on the new mobility of people and money. The New York Press, Nova York.

Silva L 1994. Os reformadores sociais na década de 1920 : alguns aspectos da atuação dos engenheiros na cidade do Rio de Janeiro. III Seminário de História da Cidade e do Urbanismo. USP/Anpur, São Carlos, SP.

Snow J 1990. Sobre a maneira de transmissão do cólera. (2a ed. brasileira). Hucitec-Abrasco, São Paulo-Rio de Janeiro.

Timms D 1971. The urban mosaic: towards a theory of residential differentiation. Cambridge University Press, Cambridge.

Vaguet A 2001. Du bon usage de l'analyse spatiale et de l'evaluation territoriale dans le spolitiques sanitaires. Natures, Sciences et Sociétés 9(4):36-42.

Vasconcellos MM 1997. Modelos de localização e sistemas de informações geográficas na assistência materna e perinatal: uma aplicação no município do Rio de Janeiro. Tese de doutorado. Coordenação dos Programas de Pós-graduação em Engenharia da UFRJ.

Velho O 1973. Introdução. In O Velho (org.). O fenômeno urbano. Zahar Editora, Rio de Janeiro.
Velho O 1975. A utopia urbana: um estudo de antropologia social. Zahar Editora, Rio de Janeiro.

Verdier N 2002. Variations sur le territoire - analyse comparée de travaux urbains: Le Havre 1789-1894, pp. 1.031-1.065. Annales: histoire, sciences sociales, no 4, juillet-août.

Vetter D 1981. A segregação residencial da população economicamente ativa na região metropolitana do Rio de Janeiro, segundo grupos de rendimento mensal. Revista Brasileira de Geografia 43(4):584-603.

Vetter D 1982. Quem se apropria dos benefícios líquidos dos investimentos do Estado em infra-estrutura urbana? Uma teoria de causação circular. In L Machado da Silva (org.). Solo urbano: tópicos sobre o uso da terra. (Série Debates Urbanos, 1). Zahar Editor, Rio de Janeiro.

Wynder EL, Cornfield J, Schroff, PD \& Doraiswami KR 1988. Estudio de los factores ambientales en el cáncer del cuello del útero, pp. 338-372. In C Buck, A Llopis, E Nájera \& M Terris (orgs.). El desafio de la epidemiologia: problemas y lecturas seleccionadas. OPAS, Washington, D.C.

Artigo apresentado em 10/10/2002

Aprovado em 1@/12/2002

Versão final apresentada em 20/12/2002 